\title{
Secondary Metabolites of Pseudomonas fluorescens CHA0 Drive Complex Non-Trophic Interactions with Bacterivorous Nematodes
}

\author{
Nina Neidig • Rüdiger J. Paul • Stefan Scheu • \\ Alexandre Jousset
}

Received: 3 November 2010 / Accepted: 7 February 2011 /Published online: 1 March 2011

(C) The Author(s) 2011. This article is published with open access at Springerlink.com

\begin{abstract}
Non-trophic interactions are increasingly recognised as a key parameter of predator-prey interactions. In soil, predation by bacterivorous nematodes is a major selective pressure shaping soil bacterial communities, and many bacteria have evolved defence mechanisms such as toxicity. In this study, we show that extracellular secondary metabolites produced by the model soil bacterium Pseudomonas fluorescens CHA0 function as a complex defence strategy against bacterivorous nematodes. Using a collection of functional mutants lacking genes for the biosynthesis of one or several extracellular metabolites, we evaluated the impact of bacterial secondary metabolites on the survival and chemotactic behaviour of the nematode Caenorhabditis elegans. Additionally, we followed up the stress status of the nematodes by measuring the activation of the abnormal DAuer Formation (DAF) stress cascade. All studied secondary metabolites contributed to the toxicity of the bacteria, with hydrogen cyanide efficiently repelling the nematodes, and both hydrogen cyanide and 2,4-DAPG functioning as nematicides. Moreover, these metabolites elicited the DAF stress response cascade of $C$. elegans, showing that they affect nematode physiology already at sublethal concentrations. The results suggest that bacterial secondary metabolites responsible for the suppression of plant pathogens strongly inhibit
\end{abstract}

\footnotetext{
N. Neidig $\cdot$ S. Scheu $\cdot$ A. Jousset $(\square)$

J.F. Blumenbach Institute of Zoology and Anthropology, Georg-August-University Göttingen,

Berliner Str. 28,

37073 Göttingen, Germany

e-mail: ajousse@gwdg.de

R. J. Paul

Animal Physiology, Westfälische-Wilhelms-University Münster,

Hindenburgplatz 55,

48143 Münster, Germany
}

bacterivorous nematodes and thus likely contribute to the resistance of bacteria against predators in soil.

\section{Introduction}

Fluorescent pseudomonads are ubiquitous soil bacteria playing an important role in promoting plant health. Many strains produce secondary metabolites, such as 2,4-diacetylphloroglucinol (DAPG), phenazines and hydrogen cyanide, thereby inhibiting soil-borne pathogens [1]. The success of these bacteria depends on various factors, such as their ability to efficiently exploit root exudates [2], but also to withstand predation by nematodes and protozoa [3, 4]. Predation is a major cause of bacterial mortality and profoundly impacts the structure and function of rootassociated bacterial communities [5, 6]. Bacteria have evolved an array of antipredatory resistance mechanisms, such as toxicity, and in soil, unpalatable or toxic strains gain competitive advantage in presence of predators $[3,7]$. Therefore, the production of secondary metabolites by biocontrol bacteria serves multiple functions, and metabolites protecting plants against pathogens improve for example bacterial resistance against predators $[8,9]$.

In this study, we investigated the role of secondary metabolites produced by the model soil bacterium Pseudomonas fluorescens CHA0 [10] interacting with the bacterivorous nematode Caenorhabditis elegans. Nematodes are major consumers of rhizosphere bacteria [5], and we hypothesised that bacterial secondary metabolites may inhibit and deter predators. Bacterial metabolites have been reported to affect nematode behaviour [11] and growth [12, 13]. Therefore, we tested if secondary metabolites produced by $P$. fluorescens function as chemotactic repellents and nematostatic compounds. At low concentrations, bacterial 
metabolites can also stress nematodes, potentially reducing reproduction rate [14]. In nematodes, reproduction and longevity are controlled by the abnormal DAuer Formation (DAF) stress response cascade. This cascade triggers immune and detoxification mechanisms [14] and increases stress resistance, but at the cost of a reduced fertility [14]. We therefore chose this cascade as a proxy for the stress status of the nematodes.

We used a set of functional mutants of $P$. fluorescens CHA0 not producing one or several secondary metabolites to investigate the relative importance of each metabolite [9] for the defence against bacterivorous nematodes. We investigated three modes of action of the metabolites. Secondary metabolites may function as repellent, and we analysed the chemotactic response of nematodes to bacterial metabolites in a food choice experiment. Moreover, we tested the relative nematicide activity of the different metabolites in a slow killing assay with functional mutants of $P$. fluorescens CHA0. Furthermore, we monitored the potential of the secondary metabolites to stress the nematodes by using GFP fusions to follow the intracellular localisation of DAF-16, the negatively regulated transcription factor of the DAF-2 insulin-like signalling pathway of C. elegans, which controls the stress response of the nematodes to environmental stressors [15].

\section{Materials and Methods}

\section{Organisms and Cultivation}

Organisms used in this study are listed in Table 1. C. elegans was routinely kept at $14^{\circ} \mathrm{C}$ on NGM agar plates (peptone $2.5 \mathrm{~g} \mathrm{~L}^{-1}, \mathrm{NaCl} 3 \mathrm{~g} \mathrm{~L}^{-1}$, agar $17 \mathrm{~g} \mathrm{~L}^{-1}, \mathrm{~K}_{3} \mathrm{PO}_{4}$ $25 \mathrm{mM}, \mathrm{MgSO}_{4} 1 \mathrm{mM}$, cholesterol $0.05 \mathrm{mg} \mathrm{L}{ }^{-1}, \mathrm{CaCl}_{2}$ $1 \mathrm{mM}$ ) seeded with Escherichia coli OP50. P. fluorescens CHA0 and derivatives were grown on nutrient agar (blood agar base $40 \mathrm{~g} \mathrm{~L}^{-1}$, yeast extract $5 \mathrm{~g} \mathrm{~L}^{-1}$ ) with appropriate antibiotics (Table 1). Each of the tested knockout mutants lacks genes for the production of one secondary metabolite but still produces the others. The $\mathrm{GacS}^{-}$mutant CHA19, which is deficient in cell signalling and does not produces any of the known secondary metabolites, was also included as reference non-toxic strain. Prior to experiments, a single colony of each tested strain was picked and incubated overnight at $28^{\circ} \mathrm{C}$ in liquid LB broth and washed twice in M9 buffer $\left(\mathrm{KH}_{2} \mathrm{PO}_{4} 3 \mathrm{~g} \mathrm{~L}^{-1}, \mathrm{Na}_{2} \mathrm{HPO}_{4} 6 \mathrm{~g} \mathrm{~L}^{-1}, \mathrm{NaCl}\right.$ $5 \mathrm{~g} \mathrm{~L}^{-1}, \mathrm{MgSO}_{4} 250 \mathrm{mg} \mathrm{L}^{-1}$ ).

\section{Preference Test}

In order to determine the potential of the different secondary metabolites as repellent against nematodes, we investigated the chemotactic response of $C$. elegans confronted with wild-type $P$. fluorescens $\mathrm{CHA} 0$ and isogenic mutants lacking genes for the production of one of the main secondary metabolites according to a standard food preference test [16] with few modifications. Ten microlitres of the tested strains $\left(\mathrm{OD}_{600}=0.5\right)$ were inoculated on one side of a 10-cm NGM agar plate. The other side of the plate was inoculated with the same amount of the wild-type reference strain $P$. fluorescens $\mathrm{CHA} 0$ producing secondary metabolites or the non-toxic strain CHA19. Additionally, two control treatments were set up with the CHA0 and CHA19 strains on both plate sides. For each treatment, five replicates were set up.

Nematodes (mixed developmental stages) were washed from the plates with M9 buffer, and $20 \mu \mathrm{L}$ of the suspension was spotted in the middle of the plate at equal distance of two bacterial drops. Nematodes present at each side of the plate were counted after $24 \mathrm{~h}$, and nematode preference for each strain against each of the two reference strains was calculated as fraction of total nematodes on the test side.

\section{Slow Killing Assay}

The impact of the different $P$. fluorescens strains on the fitness of nematodes was tested in a slow killing assay. Overnight cultures of the tested $P$. fluorescens strains were washed with $\mathrm{M} 9$ buffer and diluted to an $\mathrm{OD}_{600}$ of 0.5 . Fifteen microlitres of the bacteria were inoculated per well on $1 / 100 \mathrm{TSB}$ agar (agar, $15 \mathrm{~g} \mathrm{~L}^{-1}$, Tryptic Soy Broth $\left.300 \mathrm{mg} \mathrm{L}^{-1}\right)$ in 24-well microtitre plates for $2 \mathrm{~h}(6$ replicates each). Nematodes (mixed developmental stages) were washed with M9 buffer and added to the plates $(10 \mu \mathrm{L}$ per well, ca. 60 individuals). Dead and living nematodes were counted separately at the beginning of the experiment and after $24 \mathrm{~h}$. Nematodes without detectable movement were judged as dead.

\section{Stress Response of C. elegans-DAF-16 Translocation} Assay

The influence of toxic $P$. fluorescens $\mathrm{CHA} 0$ and its isogenic mutants on the stress response of $C$. elegans was tested using a DAF-16 translocation assay [15]: GFP-labelled nematodes (strain CF1139) were picked from NGM agar plates previously inoculated with E. coli OP50, placed on M9 plates seeded previously with $50 \mu \mathrm{L} P$. fluorescens CHA0 or derivatives (see Table 1) at an $\mathrm{OD}_{600}$ of 0.5 , and incubated at $14^{\circ} \mathrm{C}$ for $12 \mathrm{~h}$. Heat-stressed nematodes $(2 \mathrm{~h}$ at $37^{\circ} \mathrm{C}$ ) were used as positive control for DAF pathway activation [15].

In order to confirm the effect of KCN and DAPG on nematode stress status, worms were transferred to M9 agar 
Table 1 Organisms used in this study

\begin{tabular}{|c|c|c|}
\hline Strain & Characteristics & Reference \\
\hline \multicolumn{3}{|c|}{ P. fluorescens } \\
\hline CHA0 & Wild type; $\mathrm{DAPG}^{+} \mathrm{PLT}^{+} \mathrm{PRN}^{+} \mathrm{HCN}^{+} \mathrm{AprA}^{+}$ & {$[34]$} \\
\hline CHA19 & $\Delta g a c S ; \mathrm{DAPG}^{-} \mathrm{PLT}^{-} \mathrm{PRN}^{-} \mathrm{HCN}^{-} \mathrm{AprA}^{-}$ & {$[35]$} \\
\hline CHA207 & hcnA 'lacZ'; $\mathrm{DAPG}^{+} \mathrm{PLT}^{+} \mathrm{PRN}^{+} \mathrm{HCN}^{-} \mathrm{AprA}^{+}$ & {$[36]$} \\
\hline CHA631 & $\Delta p h l A \mathrm{DAPG}^{-} \mathrm{PLT}^{++} \mathrm{PRN}^{+} \mathrm{HCN}^{+} \mathrm{AprA}^{+}$ & {$[22]$} \\
\hline CHA805 & AprA - lacZ; $\mathrm{DAPG}^{+} \mathrm{PLT}^{+} \mathrm{PRN}^{+} \mathrm{HCN}^{+} \mathrm{AprA}^{-}$ & {$[27]$} \\
\hline CHA1012 & pltB::Tn5 $\mathrm{Km}^{\mathrm{r}}$; $\mathrm{DAPG}^{++} \mathrm{PLT}^{-} \mathrm{PRN}^{+} \mathrm{HCN}^{+} \mathrm{AprA}^{+}$ & {$[28]$} \\
\hline \multicolumn{3}{|l|}{ E. coli } \\
\hline OP50 & Standard laboratory strain & \\
\hline \multicolumn{3}{|l|}{ C. elegans } \\
\hline $\mathrm{N} 2$ & Wild type & \\
\hline CF1139 & $D A F-16::$ GFP (mu86) I; muls61 & {$[15]$} \\
\hline
\end{tabular}

plates supplemented with $\mathrm{KCN}$ (final concentration 80 $5,000 \mu \mathrm{M}$ ) or DAPG (final concentration 8-500 $\mu \mathrm{M}$ ) and incubated at $14^{\circ} \mathrm{C}$ for $12 \mathrm{~h}$. The degree of nuclear translocation of DAF-16::GFP was characterised on the basis of the nuclear GFP fluorescence using three levels (no, weak, strong) corresponding to a cytoplasmic, intermediate and nuclear location of DAF-16::GFP, respectively [15]. The stress level of the nematodes was evaluated on $3 \times 10$ nematodes for each bacterial strain under an epifluorescence microscope by counting the proportion of nematodes showing either a weak or strong nuclear GFP fluorescence [15].

\section{Statistical Analyses}

The results were analysed by one-way analysis of variance investigating effects of the bacterial strains, followed by Tukey's HSD test for comparison of means $(\alpha=0.05)$. Variables were checked for homogeneity of variances and percentages were arcsine square root transformed prior to the analyses. All analyses were performed using $\mathrm{R}$ 2.8.0. Error bars indicate standard error. Dose-response of the nematodes to KCN and DAPG was fitted with MichaelisMenten kinetics to determine the toxin concentration required to induce half the maximum stress reaction. All experiments were repeated with similar results.

\section{Results}

\section{Preference Test}

Orientation of $C$. elegans towards the non-toxic $P$. fluorescens strain CHA19 as well as towards the wildtype strain CHA0 significantly varied with the $P$. fluorescens mutants not producing one of the main secondary metabolites offered as alternative food substrate $\left(F_{5,20}=\right.$ $3.26, p=0.026$ and $F_{5,20}=16.37, p<0.001$, respectively;
Fig. 1). Offering the wild-type strain CHA0 as reference food source, nematodes preferred the mutants lacking genes for one or more secondary metabolites (Fig. 1A). However, the lack of single metabolites was usually not sufficient to modify significantly nematode behaviour. Only the GacS (lacking all secondary metabolites) and $\mathrm{DAPG}^{-}$strains resulted in an altered chemotactic activity (Fig. 1A). Notably, the DAPG ${ }^{-}$strain was avoided most. The chemotactic behaviour was more pronounced offering the non-toxic strain CHA19 as reference food source; the nematodes preferred this strain to the other isogenic mutants with the exception of the strains not producing HCN and extracellular protease (Fig. 1B). Strains CHA1012 (PLT $\left.{ }^{-}\right)$and CHA631 (DAPG ${ }^{-}$) were most avoided by the nematodes.

\section{Slow Killing Assay}

The slow killing assay confirmed that exoproducts of $P$. fluorescens function as nematode toxins (Fig. 2). The nontoxic strain CHA19 resulted in the lowest mortality, whereas mortality was at a maximum in the presence of strain CHA1012 $\left(\mathrm{PLT}^{-}, \mathrm{DAPG}^{++} ; F_{5,30}=29.91, p<0.001\right)$ suggesting DAPG as potent toxin killing $C$. elegans. The fraction of nematodes killed when exposed to CHA0, CHA207 and CHA631 was intermediate. Knocking out single metabolite genes was not sufficient to eliminate the nematicide activity, suggesting that all tested exoproducts contributed to bacterial toxicity and/or that some of them do not kill nematodes.

\section{Stress Response of C. elegans}

Incubation of nematodes with the wild-type strain $P$. fluorescens CHA0 resulted in nuclear translocation of DAF-16 in about $65 \%$ of the worms after $12 \mathrm{~h}$ (Fig. 3). Incubation with isogenic mutants lacking genes for the biosynthesis of one of the secondary metabolites resulted 


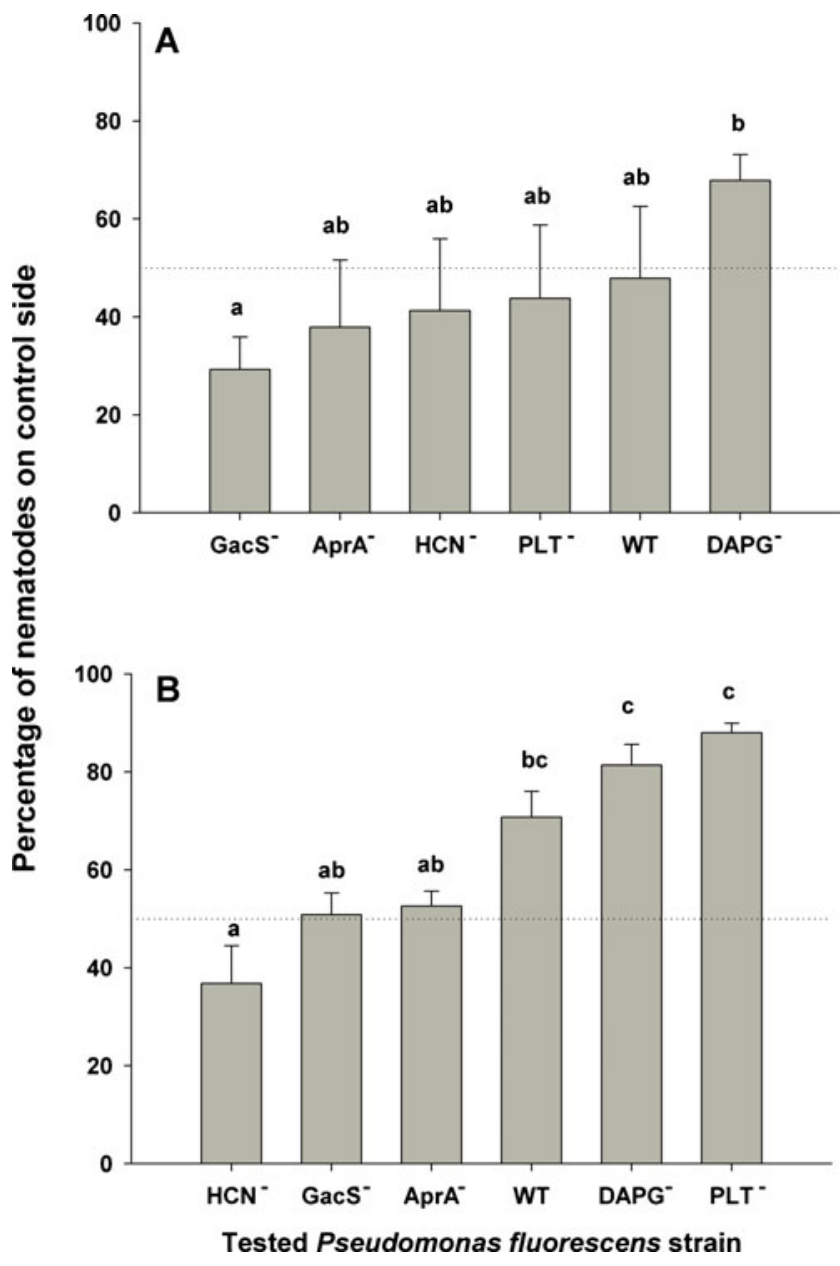

Figure 1 Chemotactic preference of $C$. elegans for different mutants of $P$. fluorescens CHA0 after $24 \mathrm{~h}$. Nematodes were offered wild-type cells or isogenic mutants deficient in the production of pyoluteorin (PLT , CHA1012), 2,4-diacetylphloroglucinol (DAPG ${ }^{-}$, CHA631), extracellular proteases $\left(\mathrm{AprA}^{-}, \mathrm{CHA} 805\right)$, hydrogen cyanide $\left(\mathrm{HCN}^{\top}\right.$, CHA207) or all extracellular metabolites (GacS , CHA19). Nematode preference was assessed against the wild-type, toxic strain CHA0 (a) or the non-toxic strain CHA19 (b). Error bars indicate \pm SE; different letters indicate significant differences between means at $p<0.05$ (Tukey's HSD test)

in a lower percentage of worms showing DAF-16 nuclear translocation $\left(F_{5,12}=14.20, p<0.001\right.$; Fig. 3), and the $\mathrm{GacS}^{-}$mutant did not elicit translocation at all, suggesting that the DAF cascade is activated by the secondary metabolites of $P$. fluorescens. In particular, mutants not producing DAPG and, to some extent, mutants not producing cyanide reduced the nuclear translocation of DAF-16 (Fig. 3), suggesting that these metabolites are main elicitors of the DAF stress response pathway. Pure DAPG and KCN elicited nuclear translocation of DAF-16 with a half saturation constant of 30 and $130 \mu \mathrm{M}$ for DAPG and KCN, respectively, confirming their effect as stressors. Notably, KCN did not stress the worms, even at $5 \mathrm{mM}$ only $80 \%$ of the worms showed nuclear translocation.

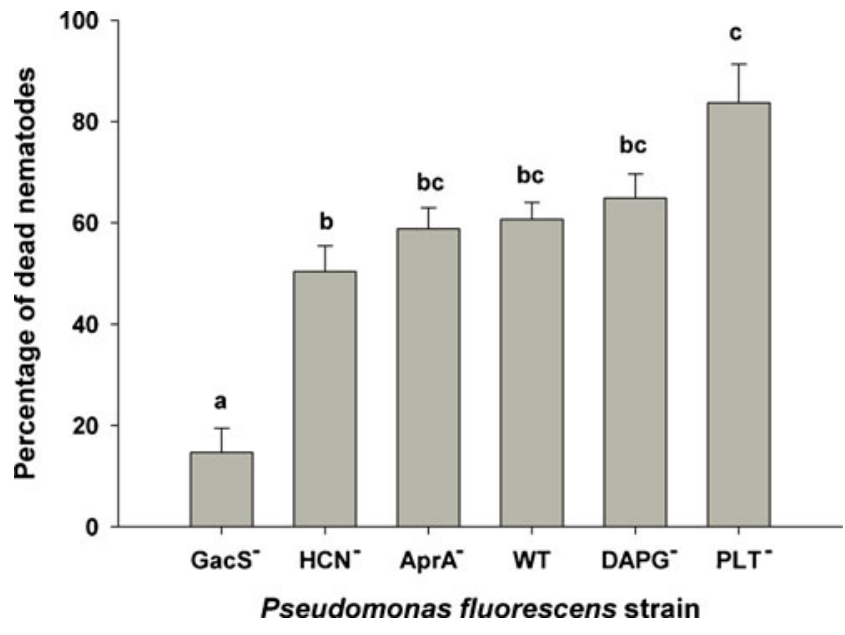

Figure 2 Toxicity of different mutants of $P$. fluorescens CHA0 against $C$. elegans in the slow killing assay after $28 \mathrm{~h}$. Nematodes were incubated with the wild-type strain or isogenic mutants deficient in the production of pyoluteorin (PLT, CHA1012), 2,4-diacetylphloroglucinol $\left(D A P G^{-}\right.$, CHA631), extracellular proteases $\left(\right.$Apr $^{-}$, CHA805), hydrogen cyanide $\left(H_{C N}\right.$, CHA207) or all secondary metabolites (GacS, CHA19). Error bars indicate $\pm \mathrm{SE}$; different letters indicate significant differences between means at $p<0.05$ (Tukey's HSD test)

A
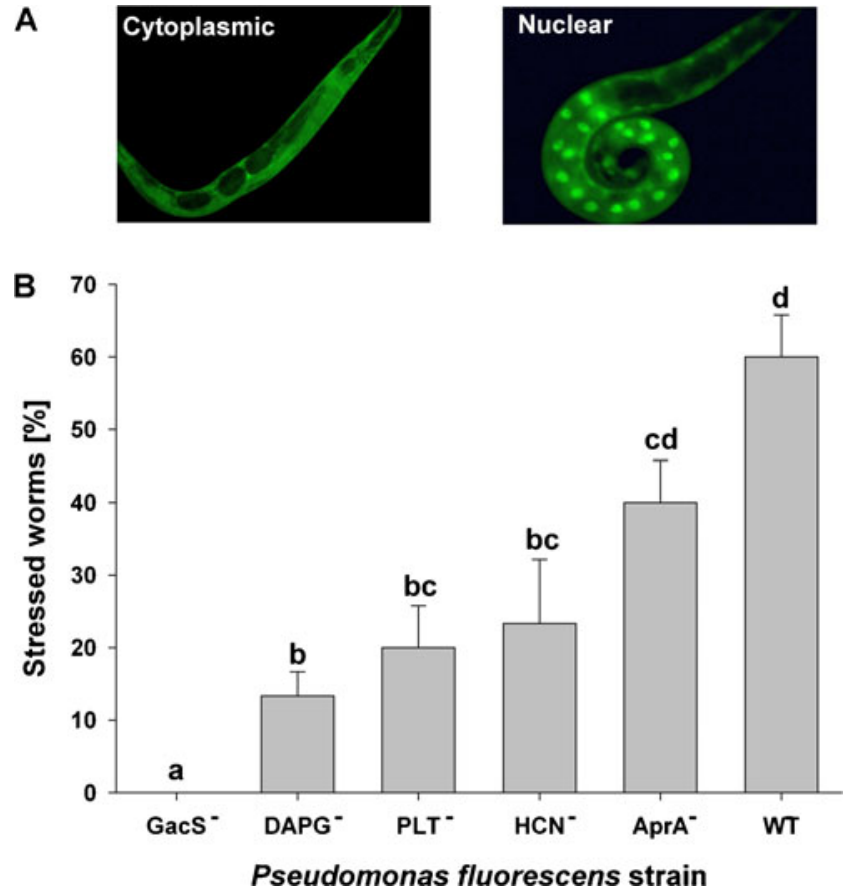

Figure 3 Effect of $P$. fluorescens CHA0 and its isogenic mutants on the activation of the DAF stress response of $C$. elegans. Stress response was assessed by following nuclear translocation of the DAF16::GFP fusion (a). Nematodes were incubated at $14^{\circ} \mathrm{C}$ on M9 plates overlayed with $P$. fluorescens strains CHA0 (WT), CHA19 (GacS ), CHA207 $\left(\mathrm{HCN}^{-}\right), \mathrm{CHA} 805\left(\mathrm{Apr}^{-}\right)$, CHA1012 (PLT) and CHA631 $\left(D A P G^{-}\right)$for $12 \mathrm{~h}$. Individuals showing translocation were counted as stressed (b). Error bars indicate $\pm \mathrm{SE}$; different letters indicate significant differences between means at $p<0.05$ (Tukey's HSD test) 


\section{Discussion}

Secondary metabolites form a key component of the defence response of soil pseudomonads against bacterivorous nematodes [4, 17], and likely contribute to improve bacterial fitness in soil. We showed that extracellular metabolites of $P$. fluorescens CHA0 drive complex interactions with nematode predators, affecting both nematode physiology and behaviour. Interestingly, the different secondary compounds differentially affected nematodes, acting as repellents, stressors or nematicides. Compared to the wild type, the effect of most mutants on nematodes was reduced. However, no single knockout was sufficient to entirely suppress bacterial toxicity suggesting that various secondary metabolites are involved in the interaction with nematodes. Mutants deficient in the production of one secondary metabolite still produce the remaining ones, and one has to consider that knocking out one compound may result in increased expression of another. In this study, we tested the role of four important and well-described secondary metabolites in the interaction with nematodes. Genome analyses of the closely related strain $P$. fluorescens $\mathrm{Pf}-5$ suggest that more secondary metabolites are produced [18], although little information is yet available. In addition, $P$. fluorescens Pf5 possesses a type VI secretion system [19], indicating that other mechanisms than extracellular secondary metabolites contribute to the interaction with nematodes.

Nematodes showed a strong negative chemotactic behaviour against the toxic wild-type and markedly preferred the toxin-deficient $P$. fluorescens strain CHA19, suggesting that secondary metabolites help to repel nematodes. Many bacteria produce defence toxins, and avoidance of toxic prey may be crucial for the survival of nematodes [20], which use a highly developed sensory system to detect toxic prey [21]. Avoidance of mutants suggests that the production of $\mathrm{HCN}$ by $P$. fluorescens plays a central role in deterring nematodes. In fact, $\mathrm{HCN}$ is a potent inhibitor of respiratory pathways and causes paralytic death of nematodes [12]. Interestingly, nematodes preferred the wild-type strain to the mutant lacking 2,4-DAPG. Knocking out the production of 2,4-DAPG results in an overproduction of pyoluteorin (PLT) and vice versa [22]. The avoidance of the DAPG deficient (and PLT overproducing) strain therefore suggests that at high concentration, this compound may function as repellent. The avoidance was even more pronounced when tested against the non-toxic $\mathrm{GacS}^{-}$strain. In this case, PLT- and DAPG-deficient mutants were the most avoided, suggesting that single overproduced secondary metabolites strongly affect the chemotactic behaviour of nematodes. However, since both mutants still produce $\mathrm{HCN}$, the effect of the tested exoproduct may have been masked. Construction of multiple knockout mutants of $P$. fluorescens producing only one single secondary metabolite may help to better understand the contrasting effect of individual secondary metabolites on nematode behaviour.

Knockout mutants deficient in the production of one of the secondary metabolites showed an altered toxicity against the nematodes in the slow killing assay. With the exception of the $\mathrm{GacS}^{-}$strain (lacking all exoproducts), the strain deficient in $\mathrm{HCN}$ production showed the lowest toxicity. Indeed, as stated above, $\mathrm{HCN}$ is known to kill effectively nematodes [12] and presumably is one of the most effective nematicides produced by $P$. fluorescens CHA0 [23]. Mutants deficient in DAPG synthesis did not significantly differ from the wild type, but interestingly, the most toxic strain was the PLT $^{-}$strain, lacking pyoluteorin and overproducing DAPG [22]. This suggests that in addition to HCN, DAPG may act as nematicide at high concentration. By inhibiting mitochondrial activity [24], DAPG plays an important role in the inhibition of competing bacteria [10] and predators $[9,25]$, but also in the control of plant-parasitic nematodes by pseudomonads $[13,26]$. Extracellular proteases are another class of compounds functioning as nematicide, and in agreement with previous studies on root knot nematodes [27], deactivation of the production of the alkaline protease AprA resulted in reduced toxicity of bacteria against $C$. elegans. Surprisingly, the PLT-deficient mutant of $P$. fluorescens was more toxic for $C$. elegans than the wild type, while the DAPG-deficient mutant presented reduced toxicity. Production of DAPG and PLT is balanced, each compound inhibiting the synthesis of the other, and PLTdeficient mutants overproduce DAPG [28]. Consequently, the higher toxicity of the PLT-deficient mutant probably was an indirect effect of DAPG overproduction, underlining the toxicity of DAPG.

In addition to nematicidal effects, bacterial secondary metabolites influenced the physiology of the nematodes. $P$. fluorescens CHA0, but not its non-toxic $\mathrm{GacS}^{-}$mutant, induced strong nuclear translocation of the DAF-16 transcription factor, indicating stress response of the nematodes after exposure to bacterial exoproducts. Nematodes possess an extensive innate immune system, and $C$. elegans uses conserved cellular signalling pathways to detect and respond to pathogens [29]. The DAF-2 stress response cascade is activated by a number of stress factors including bacterial toxins [30], and controls the investment in defence and reproduction $[31,32]$. In contrast to pathogens, which circumvent the immune response of nematodes preventing DAF-16 translocation [33], soil bacteria may benefit from activating the nematode stress response. Since the DAF cascade also regulates nematode reproduction, sublethal levels of bacterial toxins likely reduce predator fitness in the long term. Mutants not 
producing DAPG induced the lowest nuclear translocation, and tests with pure DAPG confirmed that nematodes were stressed at very low DAPG concentration, confirming the central role of this toxin in the interaction between $P$. fluorescens and nematodes. More detailed analyses of the expression of the genes downstream of the DAF cascade in the presence of bacterial toxins are needed to understand the molecular mechanisms allowing nematodes to withstand toxic bacteria in soil.

Acknowledgements We are grateful to Tim Janowitz and Peter Gerke (University of Münster) and Susanne Böning-Klein (University of Göttingen) for their assistance in the experiment on the stress response of $C$. elegans. AJ was funded by the fellowship programme of the German Federal Foundation for the Environment (DBU).

Open Access This article is distributed under the terms of the Creative Commons Attribution Noncommercial License which permits any noncommercial use, distribution, and reproduction in any medium, provided the original author(s) and source are credited.

\section{References}

1. Haas D, Defago G (2005) Biological control of soil-borne pathogens by fluorescent pseudomonads. Nat Rev Microbiol 3:307-319

2. de la Fuente L, Mavrodi DV, Thomashow LS, Weller DM (2007) Utilization of trehalose, benzoate, valerate, and seed and root exudates by genotypes of 2, 4-diacetylphloroglucinol producing Pseudomonas fluorescens. Soil Biol Biochem 39:2712-2722

3. Jousset A, Scheu S, Bonkowski M (2008) Secondary metabolite production facilitates establishment of rhizobacteria by reducing both protozoan predation and the competitive effects of indigenous bacteria. Funct Ecol 22:714-719

4. Pedersen A, Nybroe O, Winding A, Ekelund F, Bjørnlund L (2009) Bacterial feeders, the nematode Caenorhabditis elegans and the flagellate Cercomonas longicauda, have different effects on outcome of competition among the Pseudomonas biocontrol strains CHA0 and DSS73. Microb Ecol 57:501-509

5. de Mesel I, Derycke S, Moens T, Van Der Gucht K, Vincx M, Swings J (2004) Top-down impact of bacterivorous nematodes on the bacterial community structure: a microcosm study. Environ Microbiol 6:733-744

6. Rosenberg K, Bertaux J, Scheu S, Bonkowski M (2009) Soil amoeba rapidly change bacterial community composition in Arabidopsis thaliana rhizosphere. ISME J 3:675-684

7. Rønn R, Grunert J, Ekelund F (2001) Protozoan response to addition of the bacteria Mycobacterium chlorophenolicum and Pseudomonas chlororaphis to soil microcosms. Biol Fertil Soils 33:126-131

8. Mazzola M, de Bruijn I, Cohen MF, Raaijmakers JM (2009) Protozoan-induced regulation of cyclic lipopeptide biosynthesis is an effective predation defense mechanism for Pseudomonas fluorescens. Appl Environ Microbiol 75:6804-6811

9. Jousset A, Lara E, Wall LG, Valverde C (2006) Secondary metabolites help biocontrol strain Pseudomonas fluorescens CHA0 to escape predation. Appl Environ Microbiol 72:70837090

10. Keel C, Schnider U, Maurhofer M, Voisard C, Laville J, Burger U, Wirthner P, Haas D, Defago G (1992) Suppression of root diseases by Pseudomonas fluorescens CHA0: importance of the bacterial secondary metabolite 2, 4-diacetylphloroglucinol. Mol Plant Microbe Interact 5:4-13

11. Shtonda BB, Avery L (2006) Dietary choice behavior in Caenorhabditis elegans. J Exp Biol 209:89-102

12. Gallagher LA, Manoil C (2001) Pseudomonas aeruginosa PAO1 kills Caenorhabditis elegans by cyanide poisoning. J Bacteriol 183:6207-6214

13. Cronin D, Moenne-Loccoz Y, Fenton A, Dunne C, Dowling DN, Ogara F (1997) Role of 2, 4-diacetylphloroglucinol in the interactions of the biocontrol pseudomonad strain F113 with the potato cyst nematode Globodera rostochiensis. Appl Environ Microbiol 63:1357-1361

14. Henderson ST, Johnson TE (2001) daf-16 integrates developmental and environmental inputs to mediate aging in the nematode Caenorhabditis elegans. Curr Biol 11:1975-1980

15. Wolf M, Nunes F, Henkel A, Heinick A, Paul RJ (2008) The MAP kinase JNK-1 of Caenorhabditis elegans: location, activation, and influences over temperature-dependent insulin-like signaling, stress responses, and fitness. J Cell Physiol 214:721-729

16. Abada E, Sung H, Dwivedi M, Park B-J, Lee S-K, Ahnn J (2009) C. elegans behavior of preference choice on bacterial food. Mol Cells 28:209-213

17. Bjornlund L, Ronn R, Pechy-Tarr M, Maurhofer M, Keel C, Nybroe O (2009) Functional GacS in Pseudomonas DSS73 prevents digestion by Caenorhabditis elegans and protects the nematode from killer flagellates. ISME J 3:770-779

18. Loper J, Gross H (2007) Genomic analysis of antifungal metabolite production by Pseudomonas fluorescens Pf-5. Eur J Plant Pathol 119:265-278

19. Hassan KA, Johnson A, Shaffer BT, Ren QH, Kidarsa TA, Elbourne LDH, Hartney S, Duboy R, Goebel NC, Zabriskie TM, Paulsen IT, Loper JE (2010) Inactivation of the GacA response regulator in Pseudomonas fluorescens $\mathrm{Pf}-5$ has far-reaching transcriptomic consequences. Environ Microbiol 12:899-915

20. Van Voorhies WA, Fuchs J, Thomas S (2005) The longevity of Caenorhabditis elegans in soil. Biol Lett 1:247-249

21. Hilliard MA, Bargmann CI, Bazzicalupo P (2002) C. elegans responds to chemical repellents by integrating sensory inputs from the head and the tail. Curr Biol 12:730-734

22. Schnider-Keel U, Seematter A, Maurhofer M, Blumer C, Duffy B, Gigot-Bonnefoy C, Reimmann C, Notz R, Defago G, Haas D, Keel C (2000) Autoinduction of 2, 4-diacetylphloroglucinol biosynthesis in the biocontrol agent Pseudomonas fluorescens CHA0 and repression by the bacterial metabolites salicylate and pyoluteorin. J Bacteriol 182:1215-1225

23. Siddiqui IA, Shaukat SS, Sheikh IH, Khan A (2006) Role of cyanide production by Pseudomonas fluorescens CHA0 in the suppression of root-knot nematode, Meloidogyne javanica in tomato. World J Microbiol Biotechnol 22:641-650

24. Gleeson O, O'Gara F, Morrissey J (2010) The Pseudomonas fluorescens secondary metabolite 2, 4 diacetylphloroglucinol impairs mitochondrial function in Saccharomyces cerevisiae. Antonie Leeuwenhoek 97:261-273

25. Meyer SLF, Halbrendt JM, Carta LK, Skantar AM, Liu T, Abdelnabby HME, Vinyard BT (2009) Toxicity of 2, 4diacetylphloroglucinol (DAPG) to plant-parasitic and bacterialfeeding nematodes. J Nematol 41:274-280

26. Siddiqui MA, Shaukat SS (2003) Suppression of root-knot disease by Pseudomonas fluorescens CHA0 in tomato: importance of bacterial secondary metabolite, 2, 4-diacetylpholoroglucinol. Soil Biol Biochem 35:1615-1623

27. Siddiqui IA, Haas D, Heeb S (2005) Extracellular protease of Pseudomonas fluorescens CHA0, a biocontrol factor with activity against the root-knot nematode Meloidogyne incognita. Appl Environ Microbiol 71:5646-5649 
28. Baehler E, Bottiglieri M, Pechy-Tarr M, Maurhofer M, Keel C (2005) Use of green fluorescent protein-based reporters to monitor balanced production of antifungal compounds in the biocontrol agent Pseudomonas fluorescens CHA0. J Appl Microbiol 99:24-38

29. Ziegler K, Pujol N (2009) C. elegans defence mechanisms. M S Med Sci 25:497-503

30. Schulenburg H, Ewbank JJ (2007) The genetics of pathogen avoidance in Caenorhabditis elegans. Mol Microbiol 66:563-570

31. Miyata S, Begun J, Troemel ER, Ausubel FM (2008) DAF-16dependent suppression of immunity during reproduction in Caenorhabditis elegans. Genetics 178:903-918

32. Garsin DA, Villanueva JM, Begun J, Kim DH, Sifri CD, Calderwood SB, Ruvkun G, Ausubel FM (2003) Long-lived C. elegans daf-2 mutants are resistant to bacterial pathogens. Science 300:1921-1921

33. Evans EA, Kawli T, Tan MW (2008) Pseudomonas aeruginosa suppresses host Immunity by activating the DAF-2 insulin-like signaling pathway in Caenorhabditis elegans. PloS Pathogens 4
34. Voisard C, Bull CT, Keel C, Laville J, Maurhofer M, Schnider M (1994) Biocontrol of root diseases by Pseudomonas fluorescens CHA0: current concepts and experimental approaches. In: O'Gara, F, Dowling, DN, Boesten, B (eds.) Molecular ecology of rhizosphere microorganisms. $\mathrm{VCH}$ Verlagsgesellschaft $\mathrm{mbH}$, pp. $67-89$

35. Zuber S, Carruthers F, Keel C, Mattart A, Blumer C, Pessi G, Gigot-Bonnefoy C, Schnider-Keel U, Heeb S, Reimmann C, Haas D (2003) GacS sensor domains pertinent to the regulation of exoproduct formation and to the biocontrol potential of Pseudomonas fluorescens CHA0. Mol Plant Microbe Interact 16:634644

36. Blumer C, Haas D (2000) Iron regulation of the henABC genes encoding hydrogen cyanide synthase depends on the anaerobic regulator ANR rather than on the global activator GacA in Pseudomonas fluorescens CHA0. Microbiology 146:2417-2424 